\title{
Methodology for evaluating automated map generalization in commercial software
}

\author{
Jantien Stoter $^{\mathrm{a}, *}$, Dirk Burghardt ${ }^{\mathrm{b}, 1}$, Cécile Duchêne ${ }^{\mathrm{c}}$, Blanca Baella ${ }^{\mathrm{d}}$, Nico Bakker ${ }^{\mathrm{e}}$, Connie Blok ${ }^{\mathrm{a}}$, \\ Maria Pla ${ }^{\mathrm{d}}$, Nicolas Regnauld ${ }^{\mathrm{f}}$, Guillaume Touya ${ }^{\mathrm{c}}$, Stefan Schmid ${ }^{\mathrm{b}}$ \\ a ITC, Enschede, The Netherlands \\ ${ }^{\mathrm{b}}$ University of Zurich, Switzerland \\ c IGN, France \\ d ICC, Catalonia, France \\ e Kadaster, The Netherlands \\ ${ }^{\mathrm{f}}$ Ordnance Survey, Great Britain, UK
}

\section{A R T I C L E I N F O}

Keywords:

NMA requirements for automated map generalization

Evaluation of generalized data

Constraint-based generalization

State-of-the-art of generalization

\begin{abstract}
A B S T R A C T
This paper presents a methodology developed for a study to evaluate the state of the art of automated map generalization in commercial software without applying any customization. The objectives of this study are to learn more about generic and specific requirements for automated map generalization, to show possibilities and limitations of commercial generalization software, and to identify areas for further research. The methodology had to consider all types of heterogeneity to guarantee independent testing and evaluation of available generalization solutions. The paper presents the two main steps of the methodology. The first step is the analysis of map requirements for automated generalization, which consisted of sourcing representative test cases, defining map specifications in generalization constraints, harmonizing constraints across the test cases, and analyzing the types of constraints that were defined. The second step of the methodology is the evaluation of generalized outputs. In this step, three evaluation methods were integrated to balance between human and machine evaluation and to expose possible inconsistencies. In the discussion the applied methodology is evaluated and areas for further research are identified.
\end{abstract}

(c) 2009 Published by Elsevier Ltd.

\section{Introduction}

Research in automated map generalization has yielded many promising results (Mackaness, Ruas, \& Sarjakoski, 2007). At the same time, vendors face difficulties in implementing automated generalization solutions in commercial software (Stoter, 2005), which occurs for several reasons.

First, a formal definition of map specifications is lacking. Although a satisfying generalization solution can be defined in general terms-e.g., as a map that reduces the details and discerns regional patterns, that is aesthetically pleasant, and enables users to succeed in a given task (Mackaness \& Ruas, 2007)-it is difficult to specify specifications into such a format and knowledge level in such a way that they can steer the automated generalization process. Second, software vendors need map specifications that are shared by several map producers such as National Mapping Agen-

\footnotetext{
* Corresponding author. Present address: GISt, OTB, TU Delft, P.O. Box 5030, 2600 GA Delft, The Netherlands.

E-mail address: j.e.stoter@tudelft.nl (J. Stoter).

1 Present address: Institute of Cartography, Dresden University of Technology, Helmholzstr. 10, Dresden, Germany.
}

cies (NMAs) to justify their investments. Such shared generalization specifications are not easy to formulate because of differences in data models, level of detail of initial data, landscapes to be mapped, scales to be produced, etc. A final reason for the difficult implementation of automated map generalization is that generalization is a subjective process in which more than one ideal generalization result is often possible. This subjectivity in solving cartographic conflicts is a challenge to automate.

To address these difficulties, we conducted a study on the state of the art of automated map generalization in commercial software. Specifically, through the study we aimed to learn more about generic and specific map specifications of NMAs, to encourage and support vendors in implementing these specifications in commercial software, and to identify areas for further research. The study took place in the framework of EuroSDR (European Spatial Data Research), where NMAs, research institutes, and private industry work together on research topics of common interests.

The present paper focuses on the methodology that we developed to evaluate complete maps, generalized by different systems and different testers, taking into account the differing map specifications of several NMAs. The methodology had to consider all kinds of heterogeneity to guarantee independent testing and evaluation of available generalization solutions. To meet these heterogeneities, 
the methodology consisted of two main steps: requirements analysis for automated map generalization and evaluation of generalized outputs.

Our paper starts with an overview of previous research related to defining specifications for automated map generalization in Section 2. This section also defines the scope of the current study. Section 3 describes the first main step of the methodology, i.e., the requirement analysis. This step consisted of sourcing representative test cases, defining map specifications as generalization constraints, harmonizing constraints across the test cases, and analyzing the types of constraints defined. Section 4 presents the second main step of the methodology, i.e., the evaluation of generalization outputs. This step included developing and integrating three evaluation methods: expert evaluation, automated constraint-based evaluation, and qualitative comparison of outputs. The paper concludes with an evaluation of the methodology, sharing insights obtained during the tests, and identifying areas for further research (Section 5).

\section{Background}

\subsection{Previous research related to specifications for automated map generalization}

An overview of previous studies on formalizing map knowledge for automated generalization can be found in Sarjakoski (2007). Various researchers have studied specifications for automated map generalization (Foerster, Stoter, \& Kraak, 2009). Müller and Mouwes (1990) examined existing map series to conclude that "superficial" generalization knowledge exists in the form of map specifications written down for interactive generalization. Complementary to this "superficial" knowledge, cartographers use "deep" generalization knowledge to interpret superficial knowledge. This deep knowledge is much harder to automate. Rieger and Coulson (1993) carried out a survey among a group of cartographers performing interactive generalization and concluded that a common view on the classification of generalization operators does not exist. Nickerson (1991) and Kilpelaïnen (2000) acquired knowledge from experts to define rules for knowledge-based map generalization. Various studies used reverse engineering to collect generalization knowledge by comparing map objects across scales (Buttenfield (1991), Leitner and Buttenfield (1995), and Weibel (1995)). Other studies generated rules from interactive generalization carried out by a cartographic expert (Weibel (1991), Weibel, Keller, and Reichenbacher (1995), McMaster (1995), and Reichenbacher (1995)). Several studies applied machine learning techniques to convert expert knowledge into map specifications for automated generalization, e.g., Weibel et al. (1995), Plazanet, Bigolin, and Ruas (1998), Mustiere $(2001,2005)$ and Hubert and Ruas (2003). Brewer and Buttenfield (2007) ran map exercises with students, on different datasets at various scales, to provide guidelines for generalization processes.

Our study builds primarily on the research by Ruas (2001), which took place within the European Organization for Experimental Photogrammetric Research (OEEPE; the predecessor of EuroSDR) and investigated the state of the art of generalization by evaluating different interactive generalization software. Ruas's study aimed to obtain insight into generalization processes for cartographic purposes-not to evaluate generalization packages or complete generalized output. The OEEPE study tested five platforms on three generalization cases for a selection of themes. Generalization operators on individual objects or groups of objects were triggered by testers' interaction. Because of a lack of written specifications, the target maps served as examples. Templates developed for the project included lists of cartographic conflicts, operations, and algorithms.
Several of Ruas's recommendations are relevant for the methodology presented in our paper. First, a formalized description of specifications for the output maps should help to obtain better solutions. Furthermore, tests should be evaluated by a more flexible and digital method, since the manual tracing of all testers' output in Ruas's study was extremely labor-intensive. Finally, tests should use symbolization information to standardize the outputs. In our study we have implemented all of these recommendations.

\subsection{Scope of the current study}

The two main questions of our study were:

(1) What are the possibilities and limitations of commercial software systems for automated generalization with respect to NMA specifications?

(2) What different generalization solutions can be generated for one test case and why do they differ?

Several aspects defined the scope of the study.

First, the aim of the study was to obtain knowledge on different aspects of automated map generalization with respect to NMA specifications, and to discover how these are implemented in commercial software. The potential and limitations of individual systems were therefore not relevant.

Second, our study focused on map specifications of NMAs. The study did not consider specifications of map end-users, because surveys performed by NMAs among their customers showed a continuous need for traditional, paper maps representing topography at different scales. This implies that NMAs still have to produce traditional map series, and justifies our focus on NMA map specifications. Although this study is driven by large volume (paper) map production at NMAs, one should realize that the results are highly relevant for other map producers and for web mapping.

Third, our study focused on large- to mid-scale generalization, since the involved NMAs considered this the most time-consuming generalization task of current production lines.

Fourth, our study focused on complete maps, rather than on specific situations. Therefore, the generalization processes should not be a sequence of operations triggered by conflicts on individual objects or a group of objects as in Ruas's OEEPE research, but be triggered by object class (theme) or spatially indicated areas (partitions).

A final focus of the study was to limit the tests to commercially available versions of software to allow us to conclude on generalities. Consequently, research team testers, either experienced or inexperienced with the systems, were not allowed to customize the software nor to program new algorithms. This did not mean that the implementation of specifications was straightforward: all tested systems-ArcGIS (ESRI), Axpand/Genesys (Axes systems), Change, Push, Typify (University of Hannover) and Clarity (1Spatial) -provide considerable flexibility to deal with the specifications. Consequently, many decisions on how to express the specifications were left to the testers. In some systems testers had to decide on the order of addressing the specifications; in other systems they had to decide which algorithms and parameters values to use. Therefore, all tests required considerable effort to align the functionality of the systems with specific test cases. To enable vendors to show all the potentials of their system, they performed parallel tests in which they were allowed to customize and develop new algorithms.

\section{Requirement analysis}

This section presents the results of the requirements analysis. Section 3.1 describes the selection of test cases representing map 
generalization problems. Section 3.2 describes the formalization of NMA specifications for automated map generalization. Section 3.3 reports on the harmonization that was carried out to produce one generic set of formal map specifications within the context of our study. Section 3.4 analyzes the defined specifications to learn more about similarities and differences between map specifications of NMAs.

\subsection{Selecting the test cases}

The first step in the requirement analysis was the selection of test cases representing problems for automated map generalization. To meet this objective, we generated a list of outstanding map generalization problems based on the OEEPE research completed with the research team's own experience. Examples of these problems are building generalization in urban zones, mountain road generalization, solving overlapping conflicts in locally dense networks, pruning of artificial networks, and ensuring consistency between themes in particular areas such as coastal zones. Some of these problems have been tackled in research, resulting in at least partial solutions. However, we wanted to evaluate complete solutions in commercial systems, and, therefore, these problems were also identified as representative map generalization problems. We selected four test cases that included all these problems (see Table 1) provided by Ordnance Survey Great Britain (OSGB), Institute Geographique Nationale, France (IGNF), The Netherlands' Kadaster (Kadaster) and Institut Cartogràfic de Catalunya (ICC).

The NMAs of the test cases modified their datasets to prepare them as input for the generalization tests, e.g., details such as rich classifications were removed from the datasets and the datasets were translated into English. In addition, to be able to define specifications of the output maps with respect to symbolized objects and to assure uniform outputs, the NMAs defined symbols for the outputs. Fig. 1 shows cutouts of the source datasets.

\subsection{Formalizing NMA specifications for automated map generalization}

In the task of formalizing map specifications for automated generalization, we can distinguish between two stages. The first stage is to describe the specifications in a way that a user (in our case the testers of the systems) fully understand what (s)he should try to obtain with the system. The second stage is to translate these specifications in a format understandable by the generalization system. The first stage was completed by means of cycles between the data providers and the research team. The second stage was completed by the testers during the test process.

To implement research theories, we formalized map specifications of NMAs as a set of cartographic constraints to be respected. In previous research on generalization, the use of constraints is a common method to define specifications and to control and evaluate the automated generalization process. Examples are McMaster and Shea (1988), Beard (1991), Bard (2004), Barrault et al. (2001), Ware, Jones, and Thomas (2003), Burghardt and Neun (2006), and Sester (2000). Constraints express how generalization output should look without addressing the way this result should be achieved, e.g., by defining sequences of operations.
We developed a template for a uniform way to define constraints in the four test cases. In the template specific properties of the constraint can be defined such as condition to be respected and the geometry type and feature class(es) to which the constraint applies (see Appendices A-C and Table 3). The template distinguishes between constraints on one object, on two objects, and on groups of objects. An importance value indicates the importance of satisfying the specific constraint in the final output. This value does not indicate in what sequence the constraints should be solved (Ruas, 1999). Satisfying less important constraints first may be necessary to satisfy more important constraints later. For example, generalization of buildings should start with reducing density before trying to cope with overlaps, even though non-overlapping constraints are more important than density constraints. NMAs could also propose an action to support the tester in finding the most desired generalization solution. This is because in some cases NMAs know what action should be taken to meet the constraint optimally, e.g., the action "exaggerate detail" for constraint "minimal depth of protrusion of a building."

\subsection{Harmonizing constraints}

NMAs defined their map specifications for automated generalization in the developed template by analyzing text-based map specifications, software code, and cartographers' knowledge. Initially a large number of constraints were defined for the four test cases (about 250), which often covered similar situations.

In the next step we harmonized the constraints, which was needed for two reasons. Harmonization, resulting in the same constraints for similar situations, unified the tests. Once a tester had expressed the constraint for one test case, (s)he could perform the same actions to express a similar constraint for a second test case. Second, harmonization enabled us to compare results for similar constraints across the test cases.

For the harmonization, similar constraints across the four test cases were identified by carefully comparing the four constraint sets. The harmonization resulted in a list of generic constraints. A few constraints were so specific that they remained as a specific constraint. Examples are OSGB constraints addressing how buildings should be aggregated depending on the initial pattern. The harmonization process resulted in 45 generic constraints: 21 generic constraints on one object (see Appendix A), 11 constraints on two objects (see Appendix $B)$, and 13 constraints on a group of objects (see Appendix C). The harmonized constraints describe those properties of the constraints that are generically applicable. These constraints contain blank entries to be completed by NMAs to define their constraints as specification of the generic constraints. The columns in the harmonized set (e.g., class, action, importance) only contain values when the value is applicable for any case, except for the column 'Condition to be respected' which is always filled, mostly with non-specified parameter values. In all other cases NMAs can specify their classes, actions, parameter values and importance values to define their constraints as specification of the generic constraints.

Table 2 shows examples of generic constraints on one object, two objects, and a group of objects (the constraint type will be introduced in Section 3.4).

Table 1

Test cases selected for the EuroSDR research.

\begin{tabular}{|c|c|c|c|c|c|}
\hline Area type & Source dataset & Target dataset (k) & Provided by & No. of feature classes & Main feature classes \\
\hline Urban area & $1: 1250$ & $1: 25$ & OS Great Britain & 37 & Buildings, roads, river, relief \\
\hline Mountainous area & $1: 10 \mathrm{k}$ & $1: 50$ & IGN France & 23 & Village, river, land use \\
\hline Rural area & $1: 10 \mathrm{k}$ & $1: 50$ & Kadaster, NL & 29 & Small town, land use, planar partition \\
\hline Coastal area & $1: 25 \mathrm{k}$ & $1: 50$ & ICC Catalonia & 74 & Village, land use (not mosaic), hydrography \\
\hline
\end{tabular}




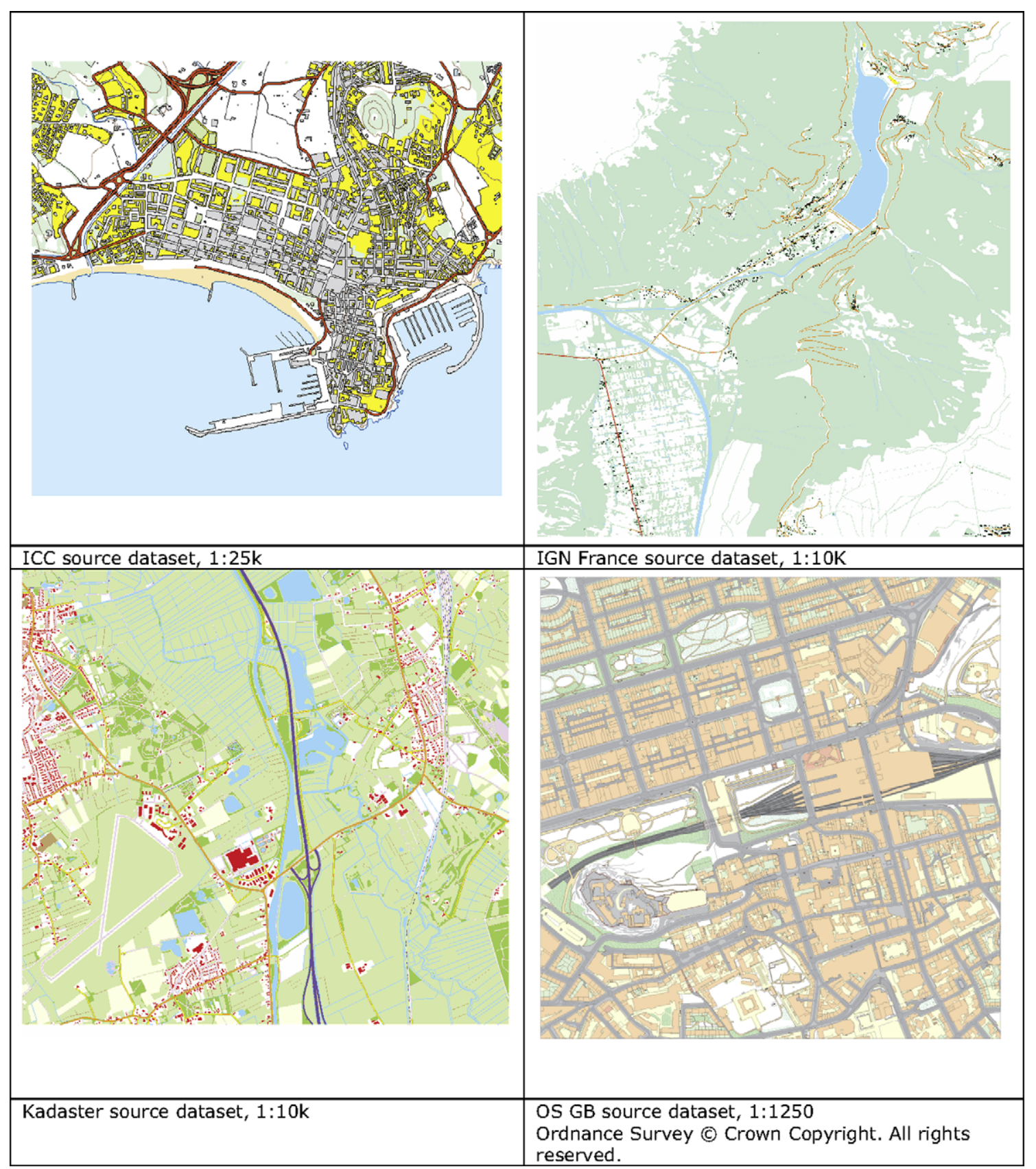

Fig. 1. Cutouts of source datasets in the EuroSDR generalization study. Maps are reduced in size.

After all four NMAs agreed on the harmonized constraints, they redefined their initial constraints as generic constraints using their own feature classes, thresholds, parameter values, and preferred actions, see Table 3 for an example of ICC (all NMA specific information is indicated in red).

\subsection{Analyzing the test cases}

To obtain more in-depth knowledge on NMA specifications for automated map generalization, the final step of the requirement analysis was the comparison of constraints across the four test cases.

For this comparison, one should realize that the constraint sets do not reflect all generalization problems of NMAs. First, the NMAs had to limit their constraints to those describing the main problems in the test area and to constraints that were more or less straightforward to formalize. Second, the constraints were defined without running any automated generalization process that would have shown both missing and unclear constraints. Last, the amount of time allocated to the testers would never enable them to set up the equivalent of a complete generalization production line, handling all specifications for one given map scale; therefore, NMAs limited their efforts on constraints that could be tackled within the context of the tests.

For the comparison of constraints among the four test cases we used three criteria: (1) the number of objects taken into account in the constraints, (2) the type of the constraints, and (3) the feature class for which the constraints were defined.

For the constraint type we distinguished between two main categories: legibility constraints and preservation constraints (Burghardt, Schmidt, and Stoter (2007)). Preservation constraints are completely satisfied at scale transitions. These are constraints 
Table 2

Examples of harmonized constraints.

\begin{tabular}{|c|c|c|}
\hline Constraint type & Property & Condition to be respected \\
\hline \multicolumn{3}{|l|}{ Constraints on one object } \\
\hline \multirow[t]{4}{*}{ Minimal dimension } & Area & Target area $>\mathrm{x}$ map $\mathrm{mm}^{2}$; target area $=$ initial area $\pm \mathrm{x} \%$ \\
\hline & Width of any part & Target width $>\mathrm{x}$ map mm \\
\hline & Area of protrusion/recess & Target area $>\mathrm{x}$ map $\mathrm{mm}^{2}$ \\
\hline & Length of an edge/line & Target length $>\mathrm{x}$ map mm \\
\hline \multirow[t]{3}{*}{ Shape } & General shape & Target shape should be similar to initial shape \\
\hline & Squareness & [Initial value of angle $=90^{\circ}\left(\right.$ tolerance $\left.\left.= \pm \mathrm{x}^{\circ}\right)\right]$ target angles $=90^{\circ}$ \\
\hline & Elongation & Target elongation = initial elongation $\pm x \%$ \\
\hline \multirow[t]{2}{*}{ Topology } & Self-intersection & (Initially, no self-intersection) no self-intersection must be created \\
\hline & Coalescence & Coalescence must be avoided \\
\hline \multirow{2}{*}{ Position/orientation } & General orientation & Target orientation $=$ initial orientation $\pm \mathrm{x} \%$ \\
\hline & Positional accuracy & Target absolute position $=$ initial absolute position $\pm x$ map $\mathrm{mm}$ \\
\hline \multicolumn{3}{|l|}{ Constraints on two objects } \\
\hline Minimal dimensions & Minimal distance & Target distance >x map mm \\
\hline Topology & Connectivity & [Initially connected] target connectivity = initial connectivity \\
\hline Position & Relative position & Target relative position $=$ initial relative position \\
\hline \multicolumn{3}{|c|}{ Constraints on a group of objects } \\
\hline Shape & Alignment & Initial alignment should be kept \\
\hline \multirow[t]{2}{*}{ Distribution \& statistics } & Distribution of characteristics & Target distribution should be similar to initial distribution \\
\hline & Density of buildings (black/white) & Target density should be equal to initial density $\pm x \%$ \\
\hline
\end{tabular}

Table 3

Example of ICC map specifications defined as constraints that extend the EuroSDR harmonized constraints.

\begin{tabular}{|c|c|c|c|}
\hline Item in constraint template & Example on one object & Example on two objects & Example on group of objects \\
\hline Constraint ID & ICC-1-22 & ICC-2-21 & ICC-3-18 \\
\hline Geometry type & Polygon & Polygon-line & Polygons \\
\hline Feature class 1 & Quay_adjacent_to_sea & Building & Building \\
\hline $\begin{array}{l}\text { Condition for object being concerned with this } \\
\text { constraint }\end{array}$ & $\begin{array}{l}\text { Depth of protrusion } \\
>1 \text { map mm }\end{array}$ & $\begin{array}{l}\text { Distance between building and road } \\
<0.5 \text { map mm }\end{array}$ & \\
\hline Constrained property & $\begin{array}{l}\text { Width of protrusion/ } \\
\text { recess }\end{array}$ & Orientation & Density of buildings (black/white ratio) \\
\hline Condition depends on initial value? & No & Yes & Yes \\
\hline Condition to be respected & $\begin{array}{l}\text { Target width } \\
>0.2 \text { map mm }\end{array}$ & Building must be parallel to road & $\begin{array}{l}\text { Target density should be equal to initial } \\
\text { density } \pm 20 \%\end{array}$ \\
\hline Action & Collapse to a line & & \\
\hline $\begin{array}{l}\text { Importance of constraint }(1-5,1 \text { is less } \\
\text { important) }\end{array}$ & 3 & 3 & 3 \\
\hline \multicolumn{4}{|l|}{ Exception } \\
\hline \multicolumn{4}{|l|}{ Schema to illustrate if needed } \\
\hline \multicolumn{4}{|l|}{ Additional for constraints on two objects: } \\
\hline Feature class 2 & & Road & \\
\hline $\begin{array}{l}\text { Condition for both objects being concerned with } \\
\text { this constraint }\end{array}$ & & Objects are parallel $\left( \pm 15^{\circ}\right)$ & \\
\hline \multicolumn{4}{|l|}{ Additional for constraints on group of objects: } \\
\hline Kind of group & & & Urban block \\
\hline $\begin{array}{l}\text { Kind of objects of the initial data composing the } \\
\text { group }\end{array}$ & & & $\begin{array}{l}\text { Buildings surrounded by minimal cycle of } \\
\text { roads (in urban areas) }\end{array}$ \\
\hline
\end{tabular}

prescribing topology, position, orientation, shape, and distribution/ statistics. Preservation constraints may be violated when operations are applied for ensuring legibility (minimal dimensions and granularity). Legibility can be investigated independently of the source dataset, while preservation always has to be evaluated in correlation with the source data. Besides legibility and preservation constraints, we identified "model generalization" constraints. These refer mainly to constraints for removing certain feature types from the data (e.g., "cycle path" in the Kadaster test case or "wall" in the ICC test case). These constraints are also for avoiding aggregation of objects with different attributes; e.g., different types of buildings in the OSGB test case should not be aggregated.

Table 4 shows the results of comparing the four constraint sets using the three criteria. Several conclusions can be drawn from this table. First, the ICC test case contains a large number of constraints compared to the other cases. This can be explained by the large number of feature classes (see Table 1 ) resulting in several similar constraints for different types of roads. Second, most constraints are defined for one object in all four cases, whereas the fewest constraints are defined for groups of objects, most likely because it was difficult to define constraints on groups of objects. Third, constraints for ensuring minimal dimensions are important in all four test cases, showing the importance of these constraints in the cartographic generalization process. Another observation is that topological constraints are defined on a more general level such as "preserve topological consistency and connectivity," "self-intersection not allowed," or "keep adjacency." It is notable that there are only a few shape constraints defined by Kadaster. Position and orientation constraints are sparsely specified by all NMAs, and they refer only to buildings. One explanation could be that buildings are expected to be displaced more often than other objects during the generalization process. A final conclusion of this analysis concerns the feature classes that were included in the constraint definitions. All four test cases contain many constraints on buildings, 


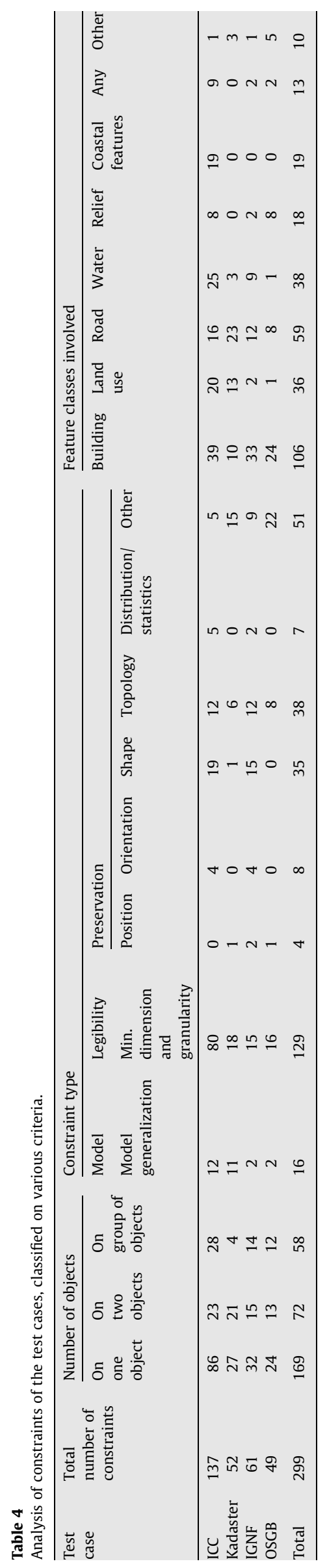

land use, and roads. The reason for the importance of these classes in the constraint sets is most likely because these are the most frequently occurring objects and the most significant for users of the map and therefore most (interactive) generalization is applied to these objects. The variation of constraints among other feature classes is a result of the relative importance of certain feature classes within the four chosen test cases; e.g., constraints on coastal features are dominant in the ICC case.

Every system was tested two to three times on all four test cases by generalization experts, who were both skilled and unskilled with the systems. In every test, the tester tried to translate all defined specifications into a form understandable by the specific software. After the testing, the outputs were evaluated using a methodology that is explained in the next section.

\section{Evaluating generalized outputs}

Evaluating generalized data can serve three main tasks: evaluation for tuning the generalization system prior to generalization, evaluation for controlling the generalization process during generalization, and evaluation for assessing the quality of generalized data after generalization (Mackaness \& Ruas, 2007). The purpose of evaluating generalized data in our study falls in the last category. However, the evaluation serves a second, more specific aim, which is learning more about generalization processes.

The methodology that we developed to evaluate the generalized outputs of the tests was driven by an observation by Mackaness and Ruas (2007). They stated that an adequate evaluation framework should be able to handle the notion that the final output is a compromise among a set of sometimes competing map objectives. Such a framework should balance between human evaluation and machine evaluation to meet the complexity of evaluation; e.g., machine evaluation can direct the user to those parts of the solution that are deemed to be unsatisfactory.

Based on this observation and motivated by the constraintbased approach of the requirement analysis of our study, we developed three integrated methods for evaluating the generalized data:

1. qualitative evaluation by cartographic experts,

2. automated constraint-based evaluation, and

3. evaluation, which visually compared different outputs for one test case

The integration was accomplished by directing experts on situations that were well, badly, or differently solved according to the automated constraint-based evaluation. In addition, the results of the visual comparison of outputs were discussed with the experts of the test cases. Conclusions of one method are also compared with results of the other two methods to identify inconsistent measuring tools.

All 34 outputs produced by the tests were evaluated. These were 27 outputs delivered by research team testers and seven outputs delivered by vendors.

The three evaluation methods are explained in Sections 4.1-4.3. More details can be found in Burghardt et al. (2008).

\subsection{Expert evaluation}

For the expert evaluation, a survey was developed that extends the earlier experts' survey of the AGENT prototype (AGENT, 2000). The survey, completed by cartographic experts of the four NMAs, focused both on global indicators and on individual constraints. The global indicators used to assess the outputs are shown in Table 5. For the assessment of the outputs on individual constraints, it appeared to be impossible to visually assess whether a threshold 
Table 5

Global indicators used in the expert survey.

Global indicators
Level of manual editions required to meet the constraints
Deviation from initial (undergeneralized) data
Preservation of the geographic characteristics of the test area (urban,
mountainous, rural, or coastal area)
Legibility
Seriousness and frequency of major detected errors
Number of positive aspects
Information reduction (ungeneralization/overgeneralization)

value, as often used in the definition of the constraints, was met. Therefore, we summarized the original constraints in a set of constraints that could be visually assessed (see Table 6). Cartographic experts assessed how these derived constraints were solved: either very badly, badly, well, or very well.

At the end of the survey, experts annotated the output maps with examples of good (g), bad (b), and differently solved generalization solutions (d) (see Fig. 2).

\subsection{Automated constraint-based evaluation}

The automated constraint-based evaluation compared the measured final value (e.g., "size') for a constraint with an ideal final value. For this evaluation an OpenJump prototype (OpenJump, 2008) was developed (see Fig. 3). This prototype implemented the automated evaluation of two legibility constraints: "target area > x map $\mathrm{mm}^{2}$ " (for one object) and "target distance $>\mathrm{x}$ map mm" (between two objects). The outcome of these evaluations is either 0 (perfect solution) or 1 (violated constraint).
Although the implementation of automated evaluation of these two constraints was more or less straightforward, the implementation for most other constraints appeared to be difficult and was therefore not realized. The reason for this is that the definition of constraints mainly aimed at being unambiguously clear for testers. Therefore, we did not endeavor to make them as formal as possible. Although for some constraints (e.g., shape and spatial distribution) it is known that the definition and the measurement are complex, a higher level of formalization could have been achieved. A constraint such as "initial and generalized shape should be similar" is less formal than the constraint "preserving width-length ratio." For this reason specifically, the constraints defined for group of objects appeared to be very difficult (if not impossible) to evaluate in an automated manner; examples are constraints on networks, patterns, and spatial distributions.

To show to what extent automated constraint-based evaluation is appropriate to identify the quality of generalized data, we applied the prototype to interactively generalized data of Kadaster, scale $1: 50 \mathrm{k}$ (the target dataset of the test case of Kadaster). In this test we assumed that the interactively generalized data, which is currently in production, is a good generalization result.

We evaluated two constraints: minimum area of buildings and minimum distance between buildings. The results for the first constraint show that $27 \%$ of the buildings are smaller than the threshold $\left(0.16 \mathrm{map} \mathrm{mm}^{2}\right)$ and are therefore evaluated as bad (see Fig. 4). However, when examining the data in more detail, we found that many "too small buildings" are just a little below the threshold size. The difference in minimum size, as mentioned in the written specifications (main source for the constraints) and as used in interactive generalization, can be explained in two ways. First, it is not possible for humans to distinguish between the threshold and the threshold plus/minus a flexibility range, and, therefore, cartographers use the thresholds with a notion of

Table 6

Individual constraints used in the expert survey.

\begin{tabular}{|c|c|c|}
\hline Constraints on one object & Constraints on two objects & Constraints on a group of objects \\
\hline Minimal dimensions & Spatial separation between features (distance) & Quantity of information (e.g., black/white ration) \\
\hline Granularity (amount of detail) & Relative position (e.g., building should remain at the same side of a road) & Spatial distribution \\
\hline Shape preservation & Consistencies between themes (e.g., contour line and river) & \\
\hline
\end{tabular}

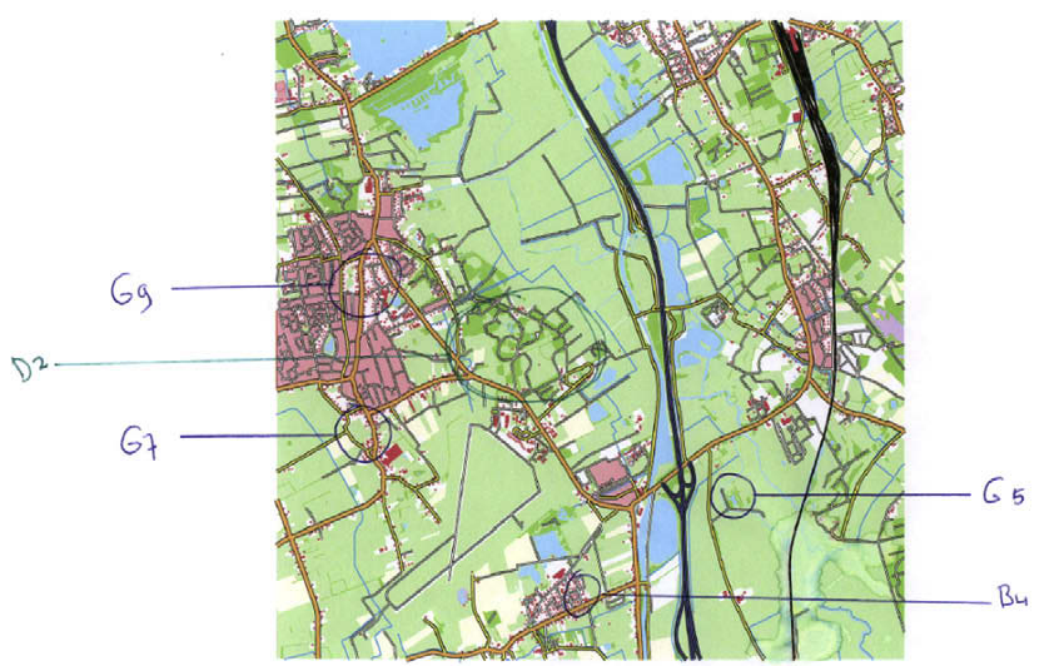

Fig. 2. Generalization output of the Kadaster test case, annotated by a cartographic expert. 


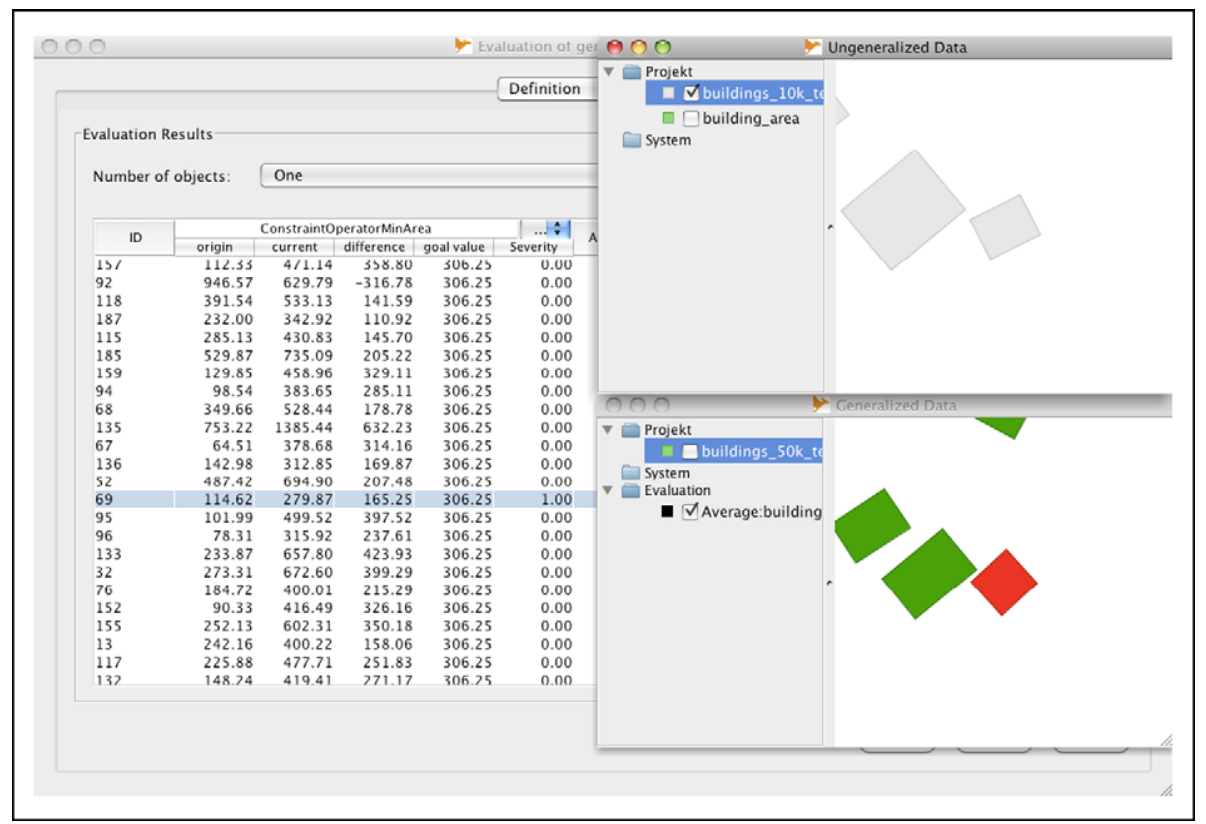

Fig. 3. Screen shot of prototype for automated constraint-based evaluation.

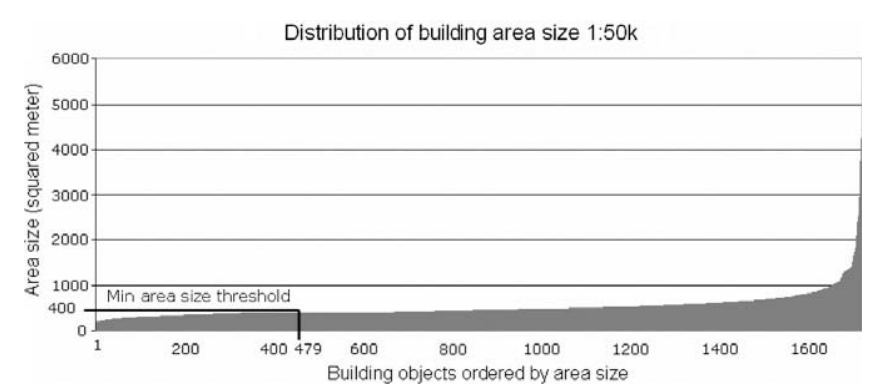

Fig. 4. Results of analyzing minimal building areas in interactively generalized data, scale $1: 50 \mathrm{k}$.

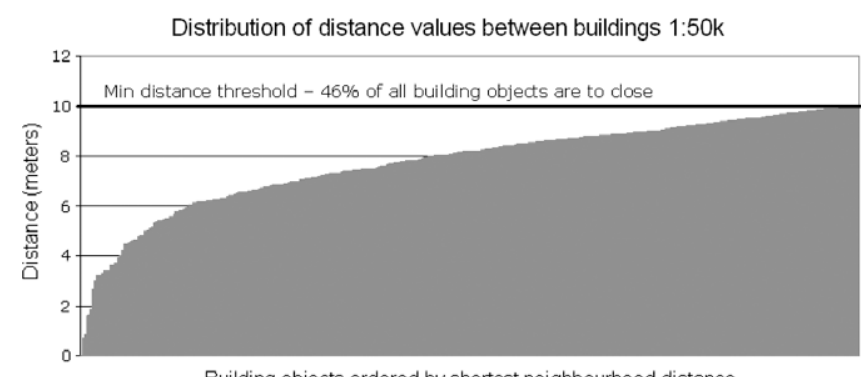

Building objects ordered by shortest neighbourhood distance

Fig. 5. Results of analyzing minimum distance between buildings constraint on interactively generalized data, scale $1: 50 \mathrm{k}$. The non-violating buildings are not shown in this graph. flexibility (Bard, 2004; Ruas, 1999). Second, in specific situations the cartographer may have chosen to relax the size constraint to meet a more important constraint, e.g., "keep important buildings."

The automated evaluation of the constraint on minimal distance ( $2 \mathrm{map} \mathrm{mm}$ ) in the interactively generalized dataset also shows many violations of the constraint. $46 \%$ of the buildings are too close to each other (Fig. 5). The violations can partly be explained by the notion of flexibility and by deliberately violating constraints to meet more important constraints, as discussed above.

However, because of the high number of violations, we examined the violated situations in more detail and encountered many situations assessed as "bad," as shown in Fig. 6b and c. To be able to distinguish between Fig. 6a, on the one hand (in which the minimum distance constraint does identify a cartographic conflict), and Fig. $6 \mathrm{~b}$ and $\mathrm{c}$ (which may be acceptable solutions), minimal distance between buildings should be further refined in constraint definitions.

The conclusion of this automated evaluation of interactively generalized data is that constraint-based evaluation requires further research to be able to describe the quality of generalized data. Future research should aim at better definition of constraints with respect to automated evaluation and better understanding of the impacts and dependencies of several constraints.

Section 5 (discussion and conclusion) contains several recommendations on how constraint-based evaluation can be improved to become more appropriate for assessing generalized data.

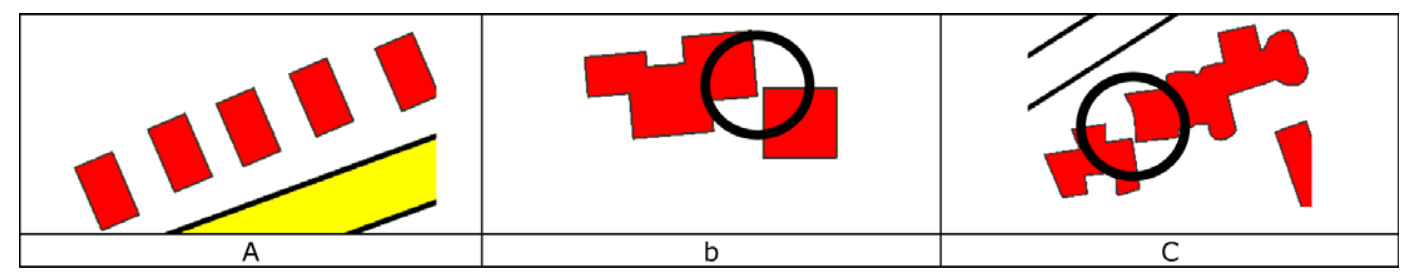

Fig. 6. Minimal distance constraint identifies unacceptable situations (a). Acceptable generalization solutions violate the distance constraint (b and c). 


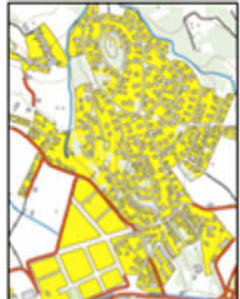

(a) Initial

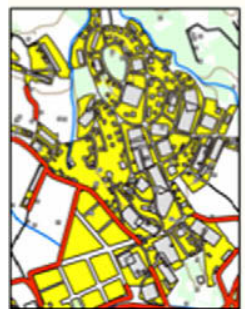

(b) Output 1

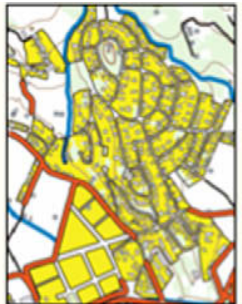

(c) Output 2

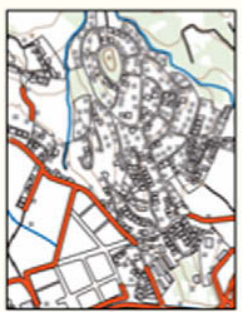

(d) Output 3

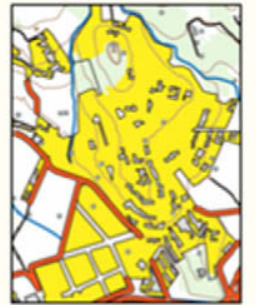

(e) Output 4

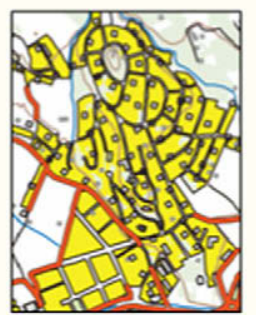

(f) Output 5

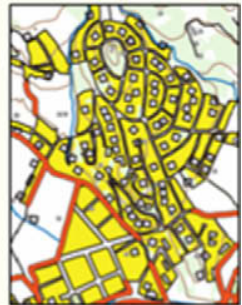

(g) Output 6

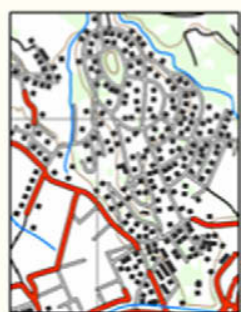

(h) Output 7

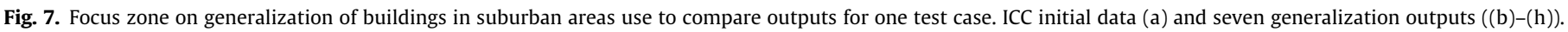

\subsection{Visual comparison of outputs}

The objective of the visual comparison of generalized data was to describe the differences between outputs for one test case from a qualitative point of view and to explain the differences. The evaluation carefully examined three to five zones per test case, which were identified by the NMAs as being of particular interest. Examples are buildings and streets in cities and suburban areas, coastlines, road interchanges, parallel roads, mountainous roads, vegetation, and dense channel networks. Fig. 7 shows an example of such a focal zone (buildings in suburban area) in the outputs of one test case. This evaluation obtained insights into the interdependencies between different constraints, the completeness and clarity of constraints, and the influence of testers' experiences with both the systems and data on the generalized output.

\section{Discussion and conclusions}

In this paper we have presented the evaluation methodology we developed to assess generalization outputs produced by various software packages and different testers, taking into account the differing specifications of the participating NMAs. From the development and application of the methodology, several conclusions can be drawn that identify issues for further research.

\subsection{Defining map specifications as constraints}

The definition and harmonization of constraints formalizing NMA map specifications provided a common view on requirements for automated map generalization. Although very time consuming, defining map specifications as a set of constraints was a good experience for the NMAs, because it highlighted the importance of explicitly defining NMA data and mapping specifications for automated processes.

The harmonized list of constraints as a result of our study is, however, not complete. The NMAs had to limit their constraints to those describing the main problems within the selected test areas and to constraints that were more or less straightforward to formalize. In addition, the constraints were defined without running any automated generalization process, which would have shown both missing and unclear constraints as well as how specific constraints work in practice. Nonetheless, the resulting set of constraints is a first attempt to define a "full" set of constraints as implementation of research theories.

\subsection{Formalizing and evaluating preservation specifications}

The preservation specifications were more difficult to formalize and to evaluate than the legibility specifications. Therefore, better understanding of preservation specifications is required to improve their formalization in constraints as well as the measurement of constraint violation. This includes a better understanding of the concepts involved (i.e., how to mathematically describe "shape") and of the changes allowed (how to mathematically describe accepted modifications). Harrie (2001) obtained such information by studying existing maps at different scales.

Another problem in evaluating preservation constraints is that a correspondence is required with the initial data. This is not an issue in 1:1 relationships; however, because of operators as selection, typification, amalgamation, and aggregation relationships may become complex, which makes it difficult to compare output data with the initial data.

The difficulty of evaluating preservation specifications was also encountered in the expert survey: it was often unclear whether a preservation constraint was assessed as "good" because the system had carefully accounted for it, or because the system had simply ignored it and at the same time had not much altered the data during the process.

\subsection{Generalizing through constraints}

Our methodology used constraints mainly to determine to what extent the outputs met the specifications. Our evaluation, which integrates three methods, has shown that this approach has an important limitation: the results for individual constraints are not always a good indicator for the quality of the overall solution. This has various explanations. First, some constraints may have been violated deliberately to enable good results for other constraints, e.g., by allowing (slightly) more displacement to avoid overlap. Second, as was observed in the automated constraintbased evaluation of interactively generalized data, one should 
assess not only if a constraint was violated but also if the violation yields an unacceptable cartographic conflict. Third, very good results for one specific constraint (e.g., minimal distance between buildings) may coincide with bad results for another constraint (e.g., building density should be kept). Fourth, a non-satisfied constraint can be due to missing functionality in a system, but can just as well be due to imprecise constraint definition. And finally, as Harrie and Weibel (2007) observed, results of constraint-based evaluation heavily depend on the defined test cases: is the constraint set complete and evenly balanced, or does it contain many constraints for very specific situations (as in the OSGB case)? Therefore, future research should aim to:

(a) revise the threshold values of constraints copied from map specifications, because their use differs in interactive and automated processes. This would require introducing the notion of flexibility in the formalization and evaluation of constraints for automated processes.

(b) evaluate the legibility constraints that account for this flexibility as a satisfaction range between 0 and 1 , instead of a Boolean outcome. Boolean values may more appropriate to identify cartographic errors. They may, however, be less appropriate for assessing the evaluation output, because they do not provide information on the degree to which the threshold is ignored.

(c) improve operators (algorithms) in generalization systems by applying the notion of satisfaction ranges.

(d) validate the constraint approach by considering how to aggregate "constraint-by-constraint" assessments for global indicators of map quality, specifically by better understanding their interdependencies and impact. This also raises questions on the domain of constraint satisfaction and violation values and on their weighting and prioritizing to make different constraints comparable and to enable aggregating them to global indicators. These issues have previously been addressed in the domain of constraint-based optimization (see Bard, 2004; Ruas, 1998, and Mackaness \& Ruas, 2007).

\subsection{Improving the constraints}

In addition to our recommendation to incorporate the notion of parameter value flexibility in improved versions of the constraints, our results suggest three specific recommendations for improving the constraint-based definition of map specifications. First, the constraints should be as formal as possible to support the generalization process as well as the automated-constraint-based evaluation. This implies that general concepts, such as shape, pattern, and urban and settlement structures, should be described formally. Second, constraints that were missing as observed from the outputs should be added. Finally, constraints that appeared to be unclear need refinement to distinguish, e.g., cartographic conflicts from acceptable solutions (compare Fig. 6a with Fig. 6b and c). Currently constraints are usually defined for geometric or thematic properties. Improvements could come from cognitive science.

\subsection{Evaluating generalization software beyond constraints}

Our study concentrated on the question of whether commercially available solutions could meet the map specifications of NMAs defined as constraints. However, during our tests several other aspects were encountered that are also relevant for assessing commercial generalization systems. For example, our testers found that in some cases topological errors were introduced during the generalization process, and that links between generalized and ungeneralized objects, required for automated evaluation, were lost in most of the outputs. Also conflict detection tools are missing. These aspects should be addressed in future tests.

Furthermore the tests highlighted difficulty to parameterize the complex algorithms and the lack of default tools, for instance default algorithm sequences or default constraints. Appropriate tools to optimally parameterize existing algorithms for a specific test case would highly improve the applicability of commercial software for a specific test case. Therefore a next research could address parameterization possibilities.

In addition, a future test should address aspects not amenable to constraints. The constraint approach is based on the consequences of scale changes. According to Mackaness and Ruas (2007), this bottom-up approach might work better for small-scale changes. In contrast, a top-down approach that meets the consequences of (large-) scale reduction by choosing appropriate representations for phenomena might work better over larger scale changes where changes are much more fundamental. A future test can provide more insights into the appropriateness of both approaches for automated map generalization. Indeed, it appeared that constraints on the final result are sometimes not sufficient to fully express without ambiguity what is expected. In some cases, specifying the expected transformation can help if this transformation is always the same and if it is well known. However fuzzy and incomplete constraints resulted in very different interpretations and solutions among the testers, which may ask for a different approach in defining the requirements for automated generalization. Furthermore, because the limited sizes of the four test cases precluded addressing the problems of dealing with large amounts of data (computational complexity, potential memory overflows that necessitate data partitioning, presence of numerous and various particular cases that make some algorithms fail, etc.), future tests should define criteria as well as measuring tools to assess scalability of systems.

And finally, future tests should quantify customization possibilities. The most realistic way to address NMA specific requirements may be to customize existing software. This requires facilities for writing extensions or for allowing integration with other systems.

In conclusion, our comprehensive study and new methodology are a significant contribution to generalization research, specifically to better defining map specifications and evaluating generalized maps. Future generalization research can extend our methodology and make use of our findings, applying improved versions of the constraint sets and re-using our carefully sourced generalization test cases.

\section{Acknowledgements}

We would like to thank all participants of the EuroSDR research, in particular we thank Peter Rosenstand (formerly KMS, Denmark), Karl-Heinrich Anders (formerly University of Hannover, Germany), Xiang Zhang (ITC, Enschede), Maarten Storm (formerly Kadaster), Annemarie Dortland and Harry Uitermark (Kadaster, The Netherlands), Magali Valdeperez, Francisco Martínez and Francisco Dávila (IGN Spain). Also we express our gratitude to our colleagues who joined us in carrying out the tests: Patrick Revell, Stuart Thom, Sheng Zhou (Ordnance Survey), Willy Kock (ITC), and Patrick Taillandier (IGN, France). We are very grateful to the vendors participating in this research for their very important contributions. We also thank the anonymous referees who reviewed an earlier submission and gave insightful suggestions for its revision and restructuring. 


\section{Appendix A. Appendix Harmonized constraints for one object}

\begin{tabular}{|c|c|c|c|c|c|c|c|c|c|}
\hline $\begin{array}{l}\text { GENERIC- } \\
\text { constraint ID }\end{array}$ & Constraint type & $\begin{array}{l}\text { Geometry } \\
\text { type }\end{array}$ & Class & $\begin{array}{l}\text { Condition for object being } \\
\text { concerned with this } \\
\text { constraint }\end{array}$ & Constrained property & $\begin{array}{l}\text { Condition } \\
\text { depends on } \\
\text { initial value? }\end{array}$ & Condition to be respected & Action & $\begin{array}{l}\text { Importance of constraint } \\
(1-5,1 \text { is less important) }\end{array}$ \\
\hline EuroSDR-1-1 & Minimal dimensions & Polygon & & & Area & No & Target area $>\mathrm{x}$ map $\mathrm{mm}^{2}$ & $\begin{array}{l}\text { IF final } \\
\text { area }<x \text { map } \\
\text { mm }^{2} \\
\text { THEN }\{\text { action }\}\end{array}$ & \\
\hline EuroSDR-1-2 & Minimal dimensions & Polygon & & & Width of any part & No & Target width >x map mm & & \\
\hline EuroSDR-1-3 & Minimal dimensions & Polygon & & Initial area $><=\mathrm{x}$ map $\mathrm{mm}^{2}$ & Area & Yes & Target area $=$ initial area $\pm x \%$ & & \\
\hline EuroSDR-1-4 & Minimal dimensions & Polygon & & Polygon contains a hole & $\begin{array}{l}\text { Area of any hole in } \\
\text { a polygon }\end{array}$ & No & Target area of hole $>\mathrm{x} \mathrm{mm}^{2}$ & & \\
\hline EuroSDR-1-5 & Minimal dimensions & Line/polygon & & & Length of an edge/line & No & Target length $>x$ map $\mathrm{mm}$ & & \\
\hline EuroSDR-1-6 & Minimal dimensions & Line/(polyline) & & & Width & No & Target width >x map mm & & \\
\hline EuroSDR-1-7 & Minimal dimensions & Line & & & Vertices density & No & Target vertices distance $>\mathrm{x}$ map $\mathrm{mm}$ & & \\
\hline EuroSDR-1-8 & Minimal dimensions & Polygon & & & Width of protrusion/recess & No & Target width $>\mathrm{x}$ map mm & & \\
\hline EuroSDR-1-9 & Minimal dimensions & Polygon & & & Depth of protrusion/recess & No & Target depth >x map mm & & \\
\hline EuroSDR-1-10 & Minimal dimensions & Polygon & & & Area of protrusion & No & Target area >x map mm² & & \\
\hline EuroSDR-1-11 & Shape & Any & & & General shape & Yes & $\begin{array}{l}\text { Target shape should be similar to } \\
\text { initial shape }\end{array}$ & & \\
\hline EuroSDR-1-12 & Shape & Any & & $\begin{array}{l}\text { 1:n Relation } \\
\text { (amalgamation) }\end{array}$ & General shape & Yes & $\begin{array}{l}\text { Target shape should be similar to } \\
\text { initial shape }\end{array}$ & & \\
\hline EuroSDR-1-13 & Shape & Polygon & & $\begin{array}{l}\text { Initial value of angle }=90^{\circ} \\
\text { (tolerance }= \pm x^{\circ} \text { ) }\end{array}$ & Squareness & Yes & Target angles $=90^{\circ}$ & & \\
\hline EuroSDR-1-14 & Shape & Polygon & & Initially high concavity & Concavity & Yes & Target shape remains concave & & \\
\hline EuroSDR-1-15 & Shape & Polygon & & & Elongation & Yes & $\begin{array}{l}\text { Target elongation = initial } \\
\text { elongation } \pm x \%\end{array}$ & & \\
\hline EuroSDR-1-16 & Topology & $\begin{array}{l}\text { Line and } \\
\text { polygon }\end{array}$ & & Initially, no self-intersection & Intersection & Yes & No self-intersection must be created & & \\
\hline EuroSDR-1-17 & Topology & $\begin{array}{l}\text { Line and } \\
\text { Polygon }\end{array}$ & & & Coalescence & No & Coalescence must be avoided & & \\
\hline EuroSDR-1-18 & Orientation & Any & & & General orientation & Yes & $\begin{array}{l}\text { Target orientation=initial } \\
\text { orientation } \pm \mathrm{x} \%\end{array}$ & & \\
\hline EuroSDR-1-19 & Position & Any & & & Positional accuracy & Yes & $\begin{array}{l}\text { Target absolute position = } \\
\text { initial absolute } \\
\text { position } \pm x \text { map } \mathrm{mm}\end{array}$ & & \\
\hline EuroSDR-1-20 & Model generalization & Any & & & Class & Yes & Target class $=$ initial class & & \\
\hline EuroSDR-1-21 & Model generalization & Any & & & Symbolization value & Yes & $\begin{array}{l}\text { Target symbolization value }=\text { initial } \\
\text { symbolization value }\end{array}$ & & \\
\hline
\end{tabular}




\section{Appendix B. Appendix Harmonized constraints on two objects}

\begin{tabular}{|c|c|c|c|c|c|c|c|c|c|c|c|c|}
\hline $\begin{array}{l}\text { GENERIC- } \\
\text { Constraint ID }\end{array}$ & $\begin{array}{l}\text { Constraint } \\
\text { type }\end{array}$ & $\begin{array}{l}\text { Geometry type } \\
\text { combination }\end{array}$ & $\begin{array}{l}\text { Class } \\
1\end{array}$ & $\begin{array}{l}\text { Condition for object } \\
\text { in class } 1 \text { being } \\
\text { concerned with this } \\
\text { constraint }\end{array}$ & $\begin{array}{l}\text { Class } \\
2\end{array}$ & $\begin{array}{l}\text { Condition for object in } \\
\text { class } 2 \text { being concerned } \\
\text { with this constraint }\end{array}$ & $\begin{array}{l}\text { Condition on both objects } \\
\text { (in the initial data) for } \\
\text { them to be concerned } \\
\text { with this constraint }\end{array}$ & $\begin{array}{l}\text { Constrained } \\
\text { property }\end{array}$ & $\begin{array}{l}\text { Condition depends } \\
\text { on initial value? }\end{array}$ & Condition to be respected & Action & $\begin{array}{l}\text { Importance of } \\
\text { constraint } \\
(1-5,1 \text { is less } \\
\text { important }) \\
\end{array}$ \\
\hline EuroSDR-2-1 & $\begin{array}{l}\text { Minimal } \\
\text { dimensions }\end{array}$ & Any-any & & & & & & $\begin{array}{l}\text { Minimal } \\
\text { distance }\end{array}$ & No & Target distance >x map mm & $\begin{array}{l}\text { IF } \\
\text { distance } \\
<\mathrm{x} \text { map } \\
\text { mm } \\
\text { THEN } \\
\{\text { action }\end{array}$ & \\
\hline EuroSDR-2-2 & $\begin{array}{l}\text { Minimal } \\
\text { dimensions }\end{array}$ & $\begin{array}{l}\text { Polygon- } \\
\text { polygon }\end{array}$ & & & & & $\begin{array}{l}\text { One class must be inside } \\
\text { within another class }\end{array}$ & $\begin{array}{l}\text { Minimal } \\
\text { area }\end{array}$ & No & Target area >x map mm2 & & \\
\hline EuroSDR-2-3 & Orientation & $\begin{array}{l}\text { Line/polygon- } \\
\text { line/polygon }\end{array}$ & & & & & Objects are parallel $\left( \pm x^{\circ}\right)$ & Orientation & Yes & $\begin{array}{l}\text { Object (class } 1 \text { ) must be } \\
\text { parallel to object (class } 2 \text { ) }\end{array}$ & & \\
\hline EuroSDR-2-4 & $\begin{array}{l}\text { Topology/ } \\
\text { position }\end{array}$ & Any-any & & & & & & $\begin{array}{l}\text { Relative } \\
\text { position }\end{array}$ & Yes & $\begin{array}{l}\text { Target relative positions = } \\
\text { initial relative positions }\end{array}$ & & \\
\hline EuroSDR-2-5 & Topology & $\begin{array}{l}\text { Line/polygon- } \\
\text { line/polygon }\end{array}$ & & & & & $\begin{array}{l}\text { Within a single feature } \\
\text { class }\end{array}$ & Intersection & No & $\begin{array}{l}\text { No other-intersections } \\
\text { must be created }\end{array}$ & & \\
\hline EuroSDR-2-6 & Topology & Line-any & & $\begin{array}{l}\text { Object (class } 1 \text { ) leads } \\
\text { to the object (class 2) }\end{array}$ & & & & Accessibility & Yes & $\begin{array}{l}\text { Target accessibility = initial } \\
\text { accessibility }\end{array}$ & & \\
\hline EuroSDR-2-7 & Topology & Line-any & & & & & Initially connected & Connectivity & Yes & $\begin{array}{l}\text { Target connectivity = initial } \\
\text { connectivity }\end{array}$ & & \\
\hline EuroSDR-2-8 & Topology & Any-any & & $\begin{array}{l}\text { Object (class1) } \\
\text { overlaps object (class } \\
\text { 2) }\end{array}$ & & $\begin{array}{l}\text { Object (class2) is under } \\
\text { object (class } 1 \text { ) }\end{array}$ & & Overlapping & No & $\begin{array}{l}\text { Target overlapping = initial } \\
\text { overlapping }\end{array}$ & & \\
\hline EuroSDR-2-9 & Topology & Any-any & & $\begin{array}{l}\text { Object (class 1) } \\
\text { contains object (class } \\
\text { 2) }\end{array}$ & & $\begin{array}{l}\text { Object (class2) is inside } \\
\text { object (class } 1 \text { ) }\end{array}$ & & $\begin{array}{l}\text { Topological } \\
\text { consistency }\end{array}$ & Yes & $\begin{array}{l}\text { Target topology relations = } \\
\text { initial topology relations }\end{array}$ & & \\
\hline EuroSDR-2-10 & Topology & $\begin{array}{l}\text { Line/polygon- } \\
\text { line/polygon }\end{array}$ & & & & & $\begin{array}{l}\text { Minimal distance }<\mathrm{x} \text { map } \\
\mathrm{mm} \text { and objects are } \\
\text { parallel } \pm \mathrm{x}^{\circ}\end{array}$ & Adjacency & Yes & $\begin{array}{l}\text { Target objects must be } \\
\text { adjacent }\end{array}$ & & \\
\hline EuroSDR-2-11 & Topology & $\begin{array}{l}\text { Line/polygon- } \\
\text { line/polygon }\end{array}$ & & & & & $\begin{array}{l}\text { Objects are topologically } \\
\text { adjacent (sharing an edge) }\end{array}$ & Adjacency & Yes & $\begin{array}{l}\text { Target topology relation }= \\
\text { initial topology relation }\end{array}$ & & \\
\hline
\end{tabular}




\section{Appendix C. Appendix Harmonized constraints for group of objects}

\begin{tabular}{|c|c|c|c|c|c|c|c|c|c|c|c|}
\hline $\begin{array}{l}\text { GENERIC- } \\
\text { Constraint ID }\end{array}$ & $\begin{array}{l}\text { Constraint } \\
\text { type }\end{array}$ & $\begin{array}{l}\text { Geometry } \\
\text { type }\end{array}$ & Class & $\begin{array}{l}\text { Kind of } \\
\text { group }\end{array}$ & $\begin{array}{l}\text { Kind of objects of the } \\
\text { initial data } \\
\text { composing the group }\end{array}$ & $\begin{array}{l}\text { Condition (in the initial } \\
\text { data) for group being } \\
\text { concerned with this } \\
\text { constraint }\end{array}$ & Constrained property & $\begin{array}{l}\text { Condition } \\
\text { depends on } \\
\text { initial } \\
\text { value? }\end{array}$ & $\begin{array}{l}\text { Condition to be respected (do } \\
\text { not forget the units) }\end{array}$ & Action & $\begin{array}{l}\text { Importance of } \\
\text { constraint }(1-5 \text {, } \\
1 \text { is less } \\
\text { important) }\end{array}$ \\
\hline EuroSDR-3-1 & $\begin{array}{l}\text { Minimal } \\
\text { dimensions }\end{array}$ & Any & & Any & Any & & $\begin{array}{l}\text { Minimal distance and } \\
\text { minimal area }\end{array}$ & No & $\begin{array}{l}\text { Distance between objects >x } \\
\text { map mm AND area of each } \\
\text { object >x map mm2 }\end{array}$ & $\begin{array}{l}\text { IF distance }<\mathrm{x} \text { map } \\
\text { mm AND area }<\text { map } \\
\text { mm2 THEN }\{\text { action }\}\end{array}$ & \\
\hline EuroSDR-3-2 & $\begin{array}{l}\text { Minimal } \\
\text { dimensions }\end{array}$ & Any & & Any & Any & & Minimal distance & No & $\begin{array}{l}\text { Distance between objects >x } \\
\text { map mm }\end{array}$ & $\begin{array}{l}\text { IF distance }<\mathrm{x} \text { map } \\
\text { mm THEN \{action\} }\end{array}$ & \\
\hline EuroSDR-3-3 & Orientation & $\begin{array}{l}\text { Point/ } \\
\text { polygon }\end{array}$ & & Alignments & & & Alignment orientation & Yes & $\begin{array}{l}\text { Target orientation should be } \\
\text { similar to initial orientation }\end{array}$ & & \\
\hline EuroSDR-3-4 & Topology & $\begin{array}{l}\text { Line and } \\
\text { polygon }\end{array}$ & & Any & Any & & Intersection & No & $\begin{array}{l}\text { No other-intersections must } \\
\text { be created }\end{array}$ & & \\
\hline EuroSDR-3-5 & Topology & $\begin{array}{l}\text { Line and } \\
\text { polygon }\end{array}$ & & Any & Any & & Connectivity & Yes & Connectivity must remain & & \\
\hline EuroSDR-3-6 & Shape & Any & & & & & Shape & Yes & $\begin{array}{l}\text { Target shape should be } \\
\text { similar to initial shape }\end{array}$ & & \\
\hline EuroSDR-3-7 & Shape & Polygon & & $\begin{array}{l}\text { Building } \\
\text { alignment }\end{array}$ & Buildings aligned & & Spatial distribution & Yes & $\begin{array}{l}\text { Target distribution should be } \\
\text { similar to initial distribution }\end{array}$ & & \\
\hline EuroSDR-3-8 & Shape & Polygon & & $\begin{array}{l}\text { Urban } \\
\text { blocks }\end{array}$ & $\begin{array}{l}\text { Buildings surrounded } \\
\text { by minimal cycle of } \\
\text { roads (in urban areas) }\end{array}$ & & Spatial distribution & Yes & $\begin{array}{l}\text { Target distribution should be } \\
\text { similar to initial distribution }\end{array}$ & & \\
\hline EuroSDR-3-9 & Shape & Line & $\begin{array}{l}\text { Contour } \\
\text { lines }\end{array}$ & Relief form & $\begin{array}{l}\text { Contour lines that } \\
\text { compose a relief form } \\
\text { (e.g., riff, valley) }\end{array}$ & & $\begin{array}{l}\text { Spatial distribution of } \\
\text { contour lines }\end{array}$ & Yes & $\begin{array}{l}\text { Target distribution of contour } \\
\text { lines should preserve the } \\
\text { relief form }\end{array}$ & & \\
\hline EuroSDR-3-10 & Shape & Polygon & & & & $\begin{array}{l}\text { Object inter-distance }<\mathrm{x} \\
\text { map mm }\end{array}$ & Shape & Yes & $\begin{array}{l}\text { The shape of derived group of } \\
\text { objects should be similar to } \\
\text { the shape of the initial group }\end{array}$ & & \\
\hline EuroSDR-3-11 & Shape & $\begin{array}{l}\text { Point/ } \\
\text { polygon }\end{array}$ & & Alignments & & & Alignment & Yes & Alignment should be kept & & \\
\hline EuroSDR-3-12 & $\begin{array}{l}\text { Distribution/ } \\
\text { statistics }\end{array}$ & Polygon & & $\begin{array}{l}\text { Urban } \\
\text { blocks }\end{array}$ & $\begin{array}{l}\text { Buildings surrounded } \\
\text { by minimal cycle of } \\
\text { roads (in urban areas) }\end{array}$ & & $\begin{array}{l}\text { Distribution of } \\
\text { characteristics of } \\
\text { buildings (shape, size, } \\
\text { function...) }\end{array}$ & Yes & $\begin{array}{l}\text { Target distribution should be } \\
\text { similar to initial distribution }\end{array}$ & & \\
\hline EuroSDR-3-13 & $\begin{array}{l}\text { Distribution/ } \\
\text { statistics }\end{array}$ & Polygon & & $\begin{array}{l}\text { Urban } \\
\text { blocks }\end{array}$ & $\begin{array}{l}\text { Buildings surrounded } \\
\text { by minimal cycle of } \\
\text { roads (in urban areas) }\end{array}$ & & $\begin{array}{l}\text { Density of buildings } \\
\text { (black/white ratio) }\end{array}$ & Yes & $\begin{array}{l}\text { Target density should be } \\
\text { equal to initial density } \pm \mathrm{x} \%\end{array}$ & & \\
\hline
\end{tabular}




\section{References}

Barrault, M., Regnauld, N., Duchêne, C., Haire, K., Baeijs, C., Demazeau, Y., et al. (2001). Integrating multi-agent, object-oriented, and algorithmic techniques for improved automated map generalisation. In Proceedings of the 20th international cartographic conference (ICC 2001) (pp. 2110-2116), 6-10 August 2001, Beijing, China. CD-ROM.

Bard, S. (2004). Quality assessment of cartographic generalisation. Transaction in GIS, 8(1), 63-81.

Beard, M. K. (1991). Constraints on rule formation. In B. P. Buttenfield \& R. B. McMaster (Eds.), Map generalisation: Making rules for knowledge representation, Longman group (pp. 121-135). London: Longman. ISBN: 0-582-08062-2.

Brewer, C. A., \& Buttenfield, B. P. (2007). Framing guidelines for multi-scale map design using databases at multiple resolutions. Cartography and Geographic Information Science, 34(1), 3-15.

Burghardt, D., Neun, M. (2006). Automated sequencing of generalisation services based on collaborative filtering. In: M. Raubal, H. J. Miller, A. U. Frank, M. Goodchild (Eds.), Geographic information science. 4th international conference (pp. 41-46), GIScience 2006, IfGIprints 28. ISBN 9-783936-616255.

Burghardt, D., Schmidt, S., Stoter, J. E. (2007). Investigations on cartographic constraint formalisation. In 10th ICA Workshop of ICA commission on generalisation and multiple representation, August 2-3, Moscow, Russia.

Burghardt, D., Schmid, S., Duchêne, C., Stoter, J., Baella, B., Regnauld, N., et al. (2008). Methodologies for the evaluation of generalised data derived with commercial available generalisation systems. In 11th ICA workshop of ICA commission on generalisation and multiple representation, 20-21 June 2008, Montpellier. <http://aci.ign.fr/BDpubli/moscow2007/Burghardt-ICAWorkshop.pdf> (accessed 3.11.08)

Buttenfield, B. P. (1991). A rule for describing line feature geometry. In B. P. Buttenfield \& R. B. McMaster (Eds.), Map generalization: Making rules for knowledge representation (pp. 150-171). Longman.

Foerster, T., Stoter, J. E., Kraak, M. -J. (2009). Challenges for automated generalisation at European mapping agencies. The Cartographic Journal, submitted for publication.

Harrie, L. (2001). An optimisation approach to cartographic generalisation. Ph.D. Thesis, Department of Technology and Society, Lund University.

Harrie, L., \& Weibel, R. (2007). Modelling the overall process of generalisation. In W. A. Mackaness, A. Ruas, \& L. T. Sarjakoski (Eds.), Chapter 4 generalisation of geographic information: Cartographic modelling and applications (pp. 67-88). Elsevier. ISBN 978-0-08-045374-3.

Hubert, F., Ruas, A. (2003). A method based on samples to capture user needs for generalisation. In 5th ICA workshop on progress in automated map generalisation, Paris, 2003. <http://www.aci.ign.fr/BDpubli/paris2003/papers/ hubert_et_al_v0.pdf> (accessed 3.11.08).

Kilpela, T. (2000). Knowledge acquisition for generalisation rules. Cartography and Geographic Information Science, 27(1), 41-50.

Leitner, M., \& Buttenfield, B. (1995). Acquisition of procedural cartographic knowledge by reverse engineering. Cartography and Geographic Information Systems, 22(3), 232-241.

McMaster, R. B., Shea, K. S. (1988). Cartographic generalisation in a digital environment: A framework for implementation in a geographic information system. In GIS/LIS proceedings (pp. 240-249), San Antonio, TX.

McMaster, R. B. (1995). Knowledge acquisition for cartographic generalization. In J. C. Mueller, J. P. Lagrange, \& R. Weibel (Eds.), GIS and generalization: Methodology and practice (pp. 161-179). London, UK: Taylor \& Francis.

Mackaness, W. A., Ruas, A., Sarjakoski, L. T. (2007). Generalisation of geographic information: Cartographic modelling and applications. Series of international cartographic association, Elsevier. ISBN 978-0-08-045374-3.
Mackaness, W. A., \& Ruas, A. (2007). Evaluation in map generalisation process. In W. A. Mackaness, A. Ruas, \& L. T. Sarjakoski (Eds.), Chapter 5 in generalisation of geographic information: Cartographic modelling and applications (pp. 89-112). Elsevier. ISBN 978-0-08-045374-3.

Müller, J. C., Mouwes, P. J. (1990). Knowledge acquisition and representation for rule based map generalisation: An example from the Netherlands. In GIS/LIS proceedings 90 (Vol. 1, pp. 58-67), Anaheim, California.

Mustière, S. (2005). Cartographic generalization of roads in a local and adaptive approach: A knowledge acquisition problem. International Journal of Geographical Information Science, 19(8-9), 937-955.

Mustière, S. (2001). Apprentissage supervisé pour la généralisation cartographique. Thèse de doctorat, Université Paris VI, France 2001.

Nickerson, B. G. (1991). Knowledge engineering for generalization. In B. Buttenfield \& R. B. McMaster (Eds.), Map generalization: Making rules for knowledge representation (pp. 40-55). London: Longman.

OpenJump. (2008). OpenJUMP - The free, Java based and open source geographic information system for the world. <http://www.openjump.org/wiki/show/ HomePage> (accessed 28.10.08).

Plazanet, C., Bigolin, N., \& Ruas, A. (1998). Experiments with learning techniques for spatial model enrichment and line generalization. Geoinformatica, 2(4), 315-333.

Reichenbacher, T. (1995) Knowledge acquisition in map generalization using interactive systems and machine learning. In Proceedings of the 17th international cartographic conference (pp. 2221-2230). Barcelona, Spain.

Rieger, M. K., \& Coulson, M. R. C. (1993). Consensus or confusion: Cartographers knowledge of generalization. Cartographica, 30(2-3), 69-80.

Ruas, A. (1998). OO-constraint modelling to automate urban generalization process. In Proceedings of the eight international symposium on spatial data handling (pp. 225-35), Vancouver, Canada, July 12-15.

Ruas, A. (1999). Modèle de généralisation de données géographiques à base de contraintes et d'autonomie. Doctoral Thesis, Université de Marne-la-Vallée.

Ruas, A. (2001). Automatic generalisation research: Learning process from interactive generalisation, OEEPE, Report no. 39.

Sarjakoski, L. T. (2007). Conceptual models of generalisation and multiple representation. In W. A. Mackaness, A. Ruas, \& L. T. Sarjakoski (Eds.). Chapter 2 of generalisation of geographic information: Cartographic modelling and applications, series of international cartographic association (pp. 11-35). Elsevier.

Sester, M. (2000). Generalisation based on least-squares adjustment. In the XIXth international congress, commission IV, international archives of photogrammetry and remote sensing (pp. 931-938), Amsterdam, The Netherlands.

Stoter, J. E (2005). Generalisation: The gap between research and practice. In Proceedings of the 8th ICA workshop on generalisation and multiple representation, 7-8 July, 2005, A Coruña, Spain, 10 pages. <http:// www.aci.ign.fr/Acoruna/Papers/Stoter.pdf> (accessed 3.11.08).

Ware, J. M., Jones, C. B., \& Thomas, N. (2003). Automated map generalisation with multiple operators: A simulated annealing approach. International Journal of Geographical Information Science, 17(8), 743-769.

Weibel, R. (1991). Amplified intelligence and rule-based systems. In B. Buttenfield \& R. B. McMaster (Eds.), Map generalization: Making rules for knowledge representation (pp. 172-186). Longman.

Weibel, R. (1995). Three essential building blocks for automated generalization. In J. Mueller, J. P. Lagrange, \& R. Weibel (Eds.), GIS and generalization: Methodology and practice (pp. 56-70). London: Taylor \& Francis.

Weibel, R., Keller, S., \& Reichenbacher, T. (1995). Overcoming the knowledge acquisition bottleneck in map generalization: The role of interactive systems and computational intelligence. In A. U. Frank \& W. Kuhn (Eds.), Spatia information theory - A theoretical basis for GIS (COSIT'95) (pp. 139-156). Berlin, Heidelberg: Springer. 